\title{
Intestinal parasites isolated in a large teaching hospital, Italy, 1 May 2006 to 31 December 2008
}

\author{
L Masucci (Imasucci@rm.unicatt.it) ${ }^{1}$, R Graffeo ${ }^{1}$, S Bani ${ }^{1}$, F Bugli ${ }^{1}$, S Boccia ${ }^{2,3}$, N Nicolotti ${ }^{2}$, B Fiori' ${ }^{1}$, G Fadda ${ }^{1}$, T Spanu \\ 1. Institute of Microbiology, Università Cattolica del Sacro Cuore, Policlinico "A. Gemelli”, Rome, Italy \\ 2. Institute of Hygiene and Preventive Medicine, Università Cattolica del Sacro Cuore, Policlinico “A. Gemelli”, Rome, Italy \\ 3. IRCCS San Raffaele Pisana, Rome, Italy
}

Citation style for this article:

Masucci L, Graffeo R, Bani S, Bugli F, Boccia S, Nicolotti N, Fiori B, Fadda G, Spanu T. Intestinal parasites isolated in a large teaching hospital, Italy, 1 May 2006 to 31 December 2008.

Euro Surveill. 2011;16(24):pii=19891. Available online: http://www.eurosurveillance.org/ViewArticle.aspx?Articleld=19891

Article published on 16 June 2011

Intestinal parasites account for the majority of parasitic diseases, particularly in endemic areas. Most are transmitted via contaminated food. Because of increased immigration and travel, enteric parasitoses are now distributed worldwide. Between May 2006 and December 2008, we examined stool specimens from 5,351 patients (4,695 Italians, 656 non-Italians) for ova and parasites using microscopy, culture techniques, and molecular methods. Stools from 594 patients $(11.1 \%)$ were contaminated and for all patients samples combined, a total of 700 intestinal parasites were counted. Ninety of the 594 infected patients had more than one parasite in their stools. Parasites causing intestinal disease occurred in $8.8 \%$ of patients. The prevalence was over twice as high among non-Italians $(26.8 \%$ vs $8.9 \%$ in Italians, $p<0.001)$ and higher in males $(13.0 \%$ vs $9.5 \%$ in females, $p=0.003)$. Most isolates were pathogenic protozoa, including in decreasing order of frequency: Blastocystis hominis, Giardia intestinalis, Entamoeba histolytica, and Cyclospora cayetanensis. The latter two species tended to be more common in Italians, although not at significant level (3.6\% (15/418) vs 1.7\% (3/176) in non-Italians, OR: 2.15 ; 95\% Cl: $0.60-11.70, p=0.22)$. Helminthes were found in 28 patients, mainly non-Italians $(5.7 \%(10 / 176)$ vs 4.3\% (18/418), OR: $1.34 ; 95 \% \mathrm{Cl}: 0.54-3.13, p=0.47)$. Ascaris lumbricoides and Hymenolepis nana were the most common. Strongyloides stercoralis, Enterobius vermicularis, Taenia spp. and Trichuris trichiura were also found. Intestinal parasites are a serious problem in developing countries, but should not be underestimated in industrialised countries.

\section{Introduction}

Enteric parasites are the most common cause of parasitic diseases, and they cause significant morbidity and mortality, particularly in endemic areas [1]. Patients with intact or compromised immunity are affected with similar frequencies [2]. Children and young adults are the most affected group, particularly in regions with limited resources and those in which observation of hygienic measures is lax [3]. Intestinal symptoms are frequent and include abdominal pain and acute or chronic diarrhoea and/or constipation, but systemic manifestations (fatigue, anaemia, weight loss, rash) are by no means uncommon. Most intestinal parasites are transmitted by the faecal-oral route as a result of the ingestion of water, vegetables, and/or soil contaminated with ova, cysts, or oocysts; in other cases (i.e. Ancylostoma duodenale) transmission occurs via the skin through direct penetration by larvae living in the soil.

The diseases caused by intestinal parasites, once considered rare phenomena confined to the tropics, are now being diagnosed with increased frequency in Europe and other industrialised countries [1]. This trend can be attributed to various factors, including globalisation of the food supply, the increased consumption of fresh foods, increased travel to developing countries, and more intensive immigration originating from these areas. Contact with other cultures has led to increased consumption of raw or undercooked foods, a potential source of parasites that could be eliminated by proper food processing [4]. Seafood is a classic example, but the rapid transport of fresh fruits and produce from developing countries has made such products more available to European consumers, and thus increased their contact with intestinal parasites. In at-risk groups, sexual practices may also represent a contributor to the transmission of parasites such as Entamoeba histolytica, Hymenolepis nana and/or Enterobius vermicularis [5].

Physicians in non-endemic areas are often poorly prepared to deal with these 'exotic' diseases. Microscopic examination of stool for ova and parasites is commonly ordered to investigate gastrointestinal complaints, eosinophilia, or liver abscesses or as part of preventive assessments of travellers, immigrants, or patients scheduled for transplantation procedures. However, the physicians who order these tests often have a limited knowledge of what they actually entail and how the results should be interpreted. Paradoxically, laboratory and physician surveys suggest that physicians often test for parasites when the likelihood of infection is low and fail to use essential tests when suspicion is high [6]. 
There is an abundance of epidemiological data on the diffusion and prevalence of intestinal parasitic diseases in developing areas $[2,7,8]$, but in industrialised countries these infections are rarely reported [9]. The microbiology laboratory of our hospital is receiving an increased number of requests for the analysis of stool specimens for ova and parasites. This trend prompted us to evaluate the distribution of intestinal parasites isolated by our laboratory over a 30-month period.

\section{Patients and methods}

\section{Patient population and study design}

This retrospective study was conducted at the Catholic University Hospital, a 1,600-bed academic medical centre located in Rome, Italy, that admits approximately 60,000 patients per year. We systematically searched the computerised database of the medical centre's central microbiology laboratory to identify all stool specimens submitted for parasitology investigation from 1 May 2006 through 31 December 2008.

\section{Laboratory methods}

All commercial products and devices described below were used in accordance with manufacturers' instructions unless otherwise stated.

Samples were stored in fresh normal saline smears. Formalin ethyl acetate concentration was performed with a Midi PARASEP kit (DiaSys Europe Ltd - Wokingham, UK) with Lugol's iodine. Smears were examined with a $40 x$ phase-contrast objective.

Permanent smears were prepared from unpreserved stool and examined with a 10ox oil-immersion objective after specific staining, which included trichrome stain (Scientific Device Laboratory, Inc.; Des Plaines, Illinois) and/or Weigert's iron hematoxylin for the detection of protozoa; modified Ziehl-Neelsen acid-fast stain for Cryptosporidium, Cyclospora, and Isospora species; and modified trichrome (chromotrope) stain for Microsporida.

We also used DNA-based methods to detect E. histolytica, E. dispar, Cryptosporidium spp., Microsporidia spp. and Cyclospora. In brief, we extracted genomic DNA from samples using the EZ1 DNA Tissue Kit (Qiagen, Valencia, CA - USA). DNA extracts were stored at $-20^{\circ} \mathrm{C}$ prior to $\mathrm{PCR}$ analysis, which was done as previously described [10-15]. PCR for Microsporidia was performed only in patients who were immunocompromised or immunosuppressed.

Stool specimens were cultured to detect the presence of certain parasites. For isolation of $E$. histolytica, we used a culture medium based on BOECK \& DRBOHLAV formulation (DiaSys Entamoeba kit, DiaSys Europe Ltd; Wokingham, UK). Cultures were incubated at $35-37^{\circ} \mathrm{C}$ for four days, and each day a drop of culture medium was examined under a $40 x$ phase-contrast objective. Cell cultures were used to detect human-infecting
Microsporidia [16]. For detection of Strongyloides stercoralis larvae, we streaked stool samples onto nutrient agar plates (1.5\% agar, 0.5\% meat extract, $1.0 \%$ peptone, $0.5 \% \mathrm{NaCl}$ ) and incubated them for at least two days at room temperature. As the larvae crawl over the agar, they carry bacteria with them, creating visible tracks [17]. When requested by clinicians, IgG antibodies to Strongyloides stercoralis were searched using a commercial ELISA (Bordier Affinity Products SA, Crissier, Switzerland).

\section{Laboratory quality control}

United Kingdom National External Quality Assessment Service (UKNEQAS - Department of Clinical Parasitology - Hospital for Tropical Diseases- London) provides specimens for faecal parasitology quality control since 2003. The quality management system of the laboratory of Microbiology is certified by Det Norske Veritas (DNV Italia S.r.l.) to conform to the quality management standard ISO 9001:2008.

\section{Data analysis}

For each case considered, the patient's demographic characteristics were obtained from the hospital and laboratory databases, and these data were used to calculate age-, sex-, and nationality-specific incidence rates for each type of pathogenic parasites.

We also reviewed the results of stool examinations for ova and parasites to determine the incremental value of examining more than one specimen. For categorical variables, results are expressed as absolute numbers or percentages. Statistical significance was determined with the chi-square test. Odds ratios (ORs) and 95\%

\section{FIGURE}

Intestinal parasite counts detected in stool samples from 594 patients, by species, Rome, Italy,

1 May 2006-31 December $2008(n=700)$

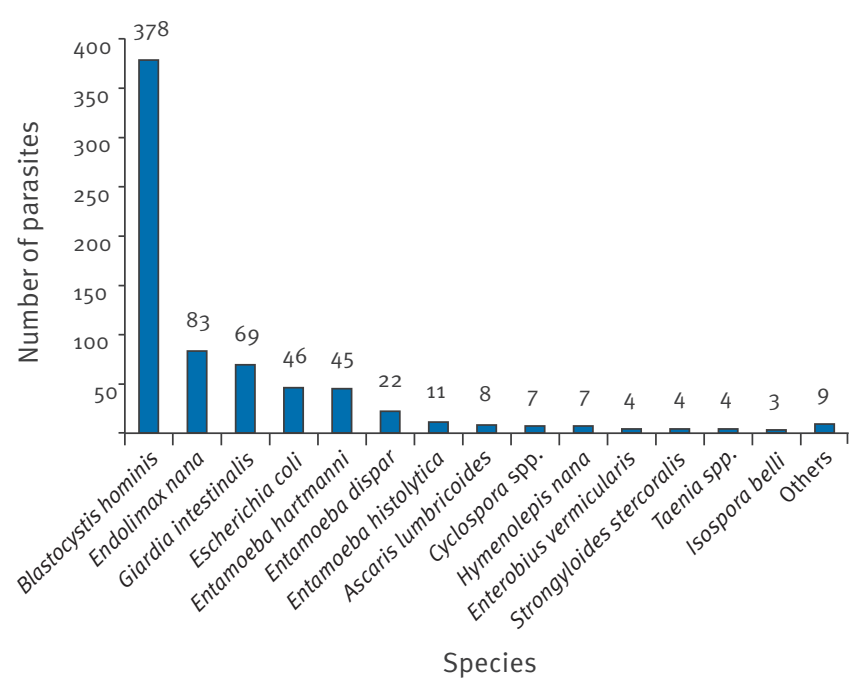

'Others' include Cryptosporidium spp. $(\mathrm{n}=2)$, Encephalitozoon intestinalis $(\mathrm{n}=2)$, Dientamoeba fragilis $(\mathrm{n}=1)$, Trichuris trichiuria $(n=1)$, Trichomonas hominis $(n=1)$, Chilomastix mesnili $(n=1)$, and lodamoeba bütschlii $(n=1)$.

Taenia spp. include Taenia saginata and T. solium. 
confidence intervals ( $\mathrm{Cls}$ ) were calculated to evaluate the strength of the associations that emerged. Twotailed tests were used to determine statistical significance; a $p$ value of $<0.05$ was considered significant.

\section{Results}

From May 2006 to December 2008, 9,456 faecal samples from 5,351 patients were examined for ova and parasites. Most patients $(87.7 \%, n=4,695)$ were of Italian nationality; the remaining $(12.3 \%, n=656)$ were born in Africa, Asia, Central and South-America. Ages ranged from o to 99 years and slightly more than half of the patients $(54.43 \%, n=2,913)$ were female. Inpatients accounted for $60 \%(n=3,216)$ of the patients in the study.

Overall, $11.1 \%(594 / 5,351)$ of patients had stools contaminated with parasites, and for all combined patients' samples, a total of 700 intestinal parasites were counted. Ninety patients $(90 / 594)$ had more than one parasite count in their stools. Enteric parasites were more commonly detected in non-Italian patients than in Italians (26.8\% $(176 / 656)$ vs $8.9 \%(418 / 4,695)$; OR: 3.01; $95 \% \mathrm{Cl}: 2.47-3.68$, p<0.001), and in males than in females $(13.0 \%(263 / 2,135)$ vs $9.5 \%(276 / 2,913)$; OR: 1.30; $95 \% \mathrm{Cl}: 1.08-1.56, p=0.003)$. Figure summarises the findings from the parasitological survey. Protozoa predominated and were identified in 96.8\% (575/594) of the subjects, while helminths were present in $4.7 \%$ (28/594).

Table 1 provides specific quantitative data regarding the association between number of stool samples examined and the successful recovery of parasites. The majority of series $(60.5 \%(3,237 / 5,351))$ consisted of only a single faecal specimen. Intestinal parasites were detected in $7.3 \%(392 / 5,351)$ of patients when either a single specimen (when only one was submitted) or the first of a series of multiple specimens was examined. Examination of a second specimen, when submitted, increased the percentage of positivity by another $1.9 \%$ of patients $(100 / 5,351)$. Examination of three faecal samples allowed the detection of parasites in another $1 \%$ of patients $(53 / 5,351)$ who had not had the first or second specimen test positive for parasites. Examination of more than three specimens, when obtained, uncovered the remaining $0.5 \%$ of patients $(29 / 5,351)$ not diagnosed in the initial specimen of a series.

When only parasites known to cause intestinal disease were considered, an overall prevalence of parasitic infections of $8.8 \%(469 / 5,351)$ was found. The prevalence of pathogenic parasites was lower $7.8 \%$ (30/387) in children aged less than five years, increased to $14 \%$ among patients aged 5-14 years, and for patients aged more than 14 years the prevalence decreased with age (Table 2).

The distribution of intestinal parasites stratified by nationality and sex is shown in Tables 3 and 4 . The prevalence of parasitic infections was about 2.6 times higher among patients in the non-Italian group (19.3\% (127/656) vs $7.3 \%(342 / 4,695)$ in the Italian group; OR: $2.66 ; 95 \%$ $\mathrm{Cl}: 2.12-3.32 ; p<0.001)$ and 1.3 times higher in males than in females $(9.9 \%(241 / 2,438)$ vs $7.8 \%(228 / 2,913)$; OR: 1.26; $95 \% \mathrm{Cl}: 1.04-1.53 ; p=0.02)$. Protozoa accounted for the vast majority of the infections, being detected in $97.6 \%(458 / 462)$ of patients harbouring pathogenic parasites. Among those, Blastocystis hominis was the most common parasite, detected in $7.1 \%(378 / 5,351)$ of the patients, particularly among non-Italians $(14.1 \%$ (93/656) vs 6.1\% $(285 / 4,695)$ in Italians; OR: $2.56 ; 95 \%$ $\mathrm{Cl}: 1.97-3.30, p<0.001)$. Although not at significant level, more males also appeared to be infected than females (7.5\% $(184 / 2,438)$ vs $6.6 \%(194 / 2,913)$; OR: $1.14 ; 95 \%$ $\mathrm{Cl}: 0.92-1.42, p=0.21)$. The level of infection by $\mathrm{B}$. hominis was lower among children less than five years of age $(2.3 \%(8 / 387)$ vs $7.5 \%(370 / 4,964)$; OR: $0.28 ; 95 \%$ $\mathrm{Cl}: 0.13-0.58, p<0.001)$ and equal among the individuals in all the other age groups. Giardia intestinalis was the second most common species. The overall prevalence of infected patients was $1.3 \%(69 / 5,351)$. Giardia intestinalis was detected more frequently in non-Italians than in Italians $(5.0 \%(33 / 656)$ vs $0.8 \%(36 / 4,695)$; OR: $6.86 ; 95 \% \mathrm{Cl}: 4.11-11.39 ; p<0.01)$, in males than in females $(1.6 \%(38 / 2,438)$ vs $0.7 \%(21 / 2,913)$; OR: 2.18 ; $95 \% \mathrm{Cl}: 1.24-3.92 ; p<0.001)$. Prevalence of giardiasis

\section{TABLE 1}

Detection of patients infected by intestinal parasites in function of number of stool samples per patient examined, Rome, Italy, 1 May 2006-31 December 2008

\begin{tabular}{|c|c|c|c|c|c|c|c|c|}
\hline \multirow[t]{2}{*}{$\begin{array}{l}\text { Number of } \\
\text { patients }\end{array}$} & \multirow{2}{*}{$\begin{array}{l}\text { Number of } \\
\text { samples examined } \\
\text { per patient }\end{array}$} & \multirow{2}{*}{$\begin{array}{c}\text { Patients testing } \\
\text { negative for intestinal } \\
\text { parasites n (\%) }\end{array}$} & \multicolumn{6}{|c|}{$\begin{array}{l}\text { Patients testing positive for intestinal parasites } \mathrm{n}(\%) \\
\text { in function of number of samples examined }\end{array}$} \\
\hline & & & 1 & 2 & 3 & 4 & 5 & $\geq 6$ \\
\hline 3,237 & 1 & $3,020(93.3)$ & $217(6.7)$ & & & & & \\
\hline 841 & 2 & 730 (86.9) & $74(8.8)$ & $37(4 \cdot 3)$ & & & & \\
\hline 949 & 3 & $811(85.5)$ & $69(7.2)$ & $32(3.4)$ & $37(3.9)$ & & & \\
\hline 49 & 5 & $35(71.4)$ & $3(6.1)$ & $8(16.3)$ & $2(4.1)$ & $0(0.0)$ & $1(2.0)$ & \\
\hline 129 & $\geq 6$ & $58(45.0)$ & $21(16.3)$ & $14(10.8)$ & $10(7.7)$ & $12(9.3)$ & $3(2.3)$ & $11(19.0)$ \\
\hline 5,351 & total & $4,776(89.2)$ & $392(7.3)$ & $100(1.9)$ & $53(1.0)$ & $15(0.3)$ & $4(0.05)$ & $11(0.2)$ \\
\hline
\end{tabular}


TABLE 2

Patients infected with intestinal parasite pathogens, by age group, Rome, Italy, 1 May 2006-31 December 2008 (n=469)

\begin{tabular}{|c|c|c|c|c|c|c|}
\hline \multirow{3}{*}{ Pathogenic parasites } & \multicolumn{6}{|c|}{ Number of patients positive for intestinal parasite pathogens } \\
\hline & $\begin{array}{l}\text { Patient age in } \\
\text { years }\end{array}$ & $<5$ & $5^{-14}$ & $15-44$ & $45-65$ & $>65$ \\
\hline & $\begin{array}{l}\text { Number of } \\
\text { patients }\end{array}$ & $(n=387)$ & $(n=410)$ & $(n=1,865)$ & $(n=1,259)$ & $(n=1,430)$ \\
\hline Ascaris lumbricoides ${ }^{a}$ & 8 & & 1 & 3 & 3 & 1 \\
\hline Blastocystis hominis ${ }^{b}$ & 378 & 8 & 35 & 142 & 89 & 104 \\
\hline Cryptosporidium spp. & 2 & & & 1 & & 1 \\
\hline Cyclospora cayetanensis & 7 & 1 & 1 & & 4 & 1 \\
\hline Dientamoeba fragilis & 1 & & & 1 & & \\
\hline Entamoeba histolytica ${ }^{\text {b }}$ & 11 & & 3 & 4 & 3 & 1 \\
\hline Enterobius vermicularis a & 4 & 1 & 1 & 1 & 1 & \\
\hline Giardia intestinalis ${ }^{b}$ & 69 & 17 & 11 & 23 & 10 & 8 \\
\hline Hymenolepis nana a & 7 & 2 & 4 & & 1 & \\
\hline Isospora belli & 3 & 1 & 1 & 1 & & \\
\hline Microsporidia & 2 & & & 1 & 1 & \\
\hline Strongyloides stercoralis a & 4 & & 1 & 1 & & 2 \\
\hline Taenia spp. ${ }^{a}$ & 4 & & & 2 & 2 & \\
\hline Trichuris trichiura ${ }^{\text {a }}$ & 1 & & & & & 1 \\
\hline Total & 501 & $30(7.7 \%)$ & $58(14.1 \%)$ & $180(9.6 \%)$ & $114(9.0 \%)$ & $119(8.3 \%)$ \\
\hline $\mathrm{p}$ value for each group distribution & & & & $<0.001$ & & \\
\hline
\end{tabular}

Total is higher than 469 , because a patient could be infected with more than one parasite species.

${ }^{a}$ Helminth.

${ }^{b}$ Pathogenic protozoan.

\section{TABLE 3}

Patients having a single intestinal parasite species, by nationality or sex, Rome, Italy, 1 May 2006-31 December 2008 (n=389)

\begin{tabular}{|c|c|c|c|c|c|}
\hline & \multirow[b]{2}{*}{ Total } & \multicolumn{4}{|c|}{ Number of positive patients that were: } \\
\hline & & Italians $(n=4,695)$ & $\begin{array}{l}\text { Non-Italians } \\
\quad(\mathrm{n}=656)\end{array}$ & Female $(n=2,913)$ & Male $(n=2,438)$ \\
\hline Ascaris lumbricoides & 7 & 4 & 3 & 5 & 2 \\
\hline Blastocystis hominis & 305 & 250 & 55 & 163 & 142 \\
\hline Cryptosporidium spp & 1 & 0 & 1 & 1 & 0 \\
\hline Cyclospora cayetanensis & 2 & 2 & 0 & 1 & 1 \\
\hline Dientamoeba fragilis & 1 & 0 & 1 & o & 1 \\
\hline Encephalitozoon intestinalis & 2 & 2 & o & 0 & 2 \\
\hline Entamoeba histolytica & 6 & 6 & 0 & 3 & 3 \\
\hline Enterobius vermicularis & 3 & 3 & 0 & 2 & 1 \\
\hline Giardia intestinalis & 52 & 30 & 22 & 15 & 37 \\
\hline Hymenolepis nana & 1 & 1 & 0 & 0 & 1 \\
\hline Isospora belli & 2 & 0 & 2 & 1 & 1 \\
\hline Strongyloides stercoralis & 2 & 2 & 0 & 1 & 1 \\
\hline Taenia spp. & 4 & 3 & 1 & 3 & 1 \\
\hline Trichuris trichiura & 1 & 0 & 1 & 1 & 0 \\
\hline Total & 389 & $303(6.4 \%)$ & $86(13.1 \%)$ & $196(6.7 \%)$ & $193(7.9 \%)$ \\
\hline$p$ value & & \multicolumn{2}{|c|}{$<0.001$} & \multicolumn{2}{|c|}{0.11} \\
\hline
\end{tabular}

Taenia spp. include Taenia saginata or solium. 
was highest in children under five years of age $(4.4 \%$ (17/387); OR: 6.81; 95\% Cl: 3.27-14.14; $p<0.001)$ and in people aged 5-14 years (2.7\% (11/410); OR: $4.09 ; 95 \%$ $\mathrm{Cl}: 1.73-9.21, p<0.001)$, and lowest in people aged 45 years or more (0.7\% $(18 / 2,689)$; OR: 1 , reference group). $E$. histolytica was the third most common species; it was isolated from 11 patients, all but one, Italians. It was detected more commonly in males. The fourth common species was Cyclospora cayetanensis, which was detected in seven patients, five were Italians, and three of these denied travel to endemic areas within the previous 12 months. Encephalitozoon intestinalis and Cryptosporidium parvum were detected in faecal samples of four HIV-infected patients. As regard to helminthes, nematodes such as Ascaris lumbricoides, Strongyloides stercoralis, Enterobius vermicularis and Trichiuris trichiuria were identified in 17 patients, of whom 10 were Italians, while the plathelminthes Hymenolepis nana and Taenia species were responsible for 11 infections which occurred in seven Italians with no history of travel, and four non-Italians, three of whom were adopted children from endemic areas.

\section{TABLE 4}

Patients with mixed infections, by combinations of pathogenic parasites, by patient nationality or sex, Rome, Italy, 1 May 2006-31 December $2008(n=80)$

\begin{tabular}{|c|c|c|c|c|c|}
\hline \multirow[b]{2}{*}{ Pathogenic parasites } & \multicolumn{5}{|c|}{ Patients } \\
\hline & Total & $\begin{array}{l}\text { Italians } \\
(n=4,695)\end{array}$ & $\begin{array}{l}\text { Non-Italians } \\
(\mathrm{n}=656)\end{array}$ & $\begin{array}{l}\text { Female } \\
(n=2,913)\end{array}$ & $\begin{array}{c}\text { Male } \\
(n=2,438)\end{array}$ \\
\hline Blastocystis hominis/Ascaris lumbricoides & 1 & 0 & 1 & 1 & 0 \\
\hline B. hominis/Cryptosporidium parvum & 1 & 1 & 0 & 0 & 1 \\
\hline B. hominis/Cyclospora cayetanensis & 4 & 2 & 2 & 2 & 2 \\
\hline B. hominis/Endolimax nana & 23 & 15 & 8 & 10 & 13 \\
\hline B. hominis/E. nana/Escherichia coli & 1 & 0 & 1 & 1 & 0 \\
\hline B. hominis/E. nana/E. coli/Entamoeba hartmanni & 1 & 0 & 1 & 1 & 0 \\
\hline B. hominis/E. nana/E. hartmanni & 2 & o & 2 & o & 2 \\
\hline B. hominis/E. nana/Entamoeba histolytica & 1 & 0 & 1 & 0 & 1 \\
\hline B. hominis/E. nana/Giardia intestinalis & 2 & 1 & 1 & 2 & 0 \\
\hline B. hominis/E. nana/Hymenolepis nana & 1 & 1 & 0 & 0 & 1 \\
\hline B. hominis/E. nana/E. coli & 1 & 0 & 1 & 1 & 0 \\
\hline B. hominis/E. coli & 11 & 3 & 8 & 5 & 6 \\
\hline B. hominis/E. coli/G. intestinalis & 2 & 0 & 2 & 1 & 1 \\
\hline B. hominis/Entamoeba dispar & 2 & 2 & 0 & 0 & 2 \\
\hline B. hominis/E. dispar/G. intestinalis & 1 & 1 & 0 & 0 & 1 \\
\hline B. hominis/E. hartmanni & 6 & 3 & 3 & 4 & 2 \\
\hline B. hominis/E. histolytica & 2 & 2 & 0 & 0 & 2 \\
\hline B. hominis/E. histolytica/G. intestinalis & 1 & 1 & 0 & 1 & 0 \\
\hline B. hominis/Enterobius vermicularis & 1 & 1 & 0 & 0 & 1 \\
\hline B. hominis/G. intestinalis & 1 & 0 & 1 & 0 & 1 \\
\hline B. hominis/G. intestinalis & 4 & 2 & 2 & 1 & 3 \\
\hline $\begin{array}{l}\text { B. hominis/H. nana/G. intestinalis/Strongyloides } \\
\text { stercoralis }\end{array}$ & 1 & 0 & 1 & 0 & 1 \\
\hline B. hominis/H. nana & 1 & 0 & 1 & 1 & 0 \\
\hline B. hominis/H. nana/G. intestinalis & 1 & 0 & 1 & 0 & 1 \\
\hline B. hominis/S. stercoralis & 1 & 0 & 1 & 0 & 1 \\
\hline C. cayetanensis/E. hartmanni & 1 & 1 & 0 & 0 & 1 \\
\hline E. histolytica/E. nana & 1 & 1 & o & 0 & 1 \\
\hline G. intestinalis/E. coli & 1 & 0 & 1 & 0 & 1 \\
\hline G. intestinalis/H. nana & 1 & 1 & 0 & 0 & 1 \\
\hline G. intestinalis/lodamoeba Butschlii & 1 & 0 & 1 & 0 & 1 \\
\hline G. intestinalis/Isospora belli & 1 & 0 & 1 & 1 & 0 \\
\hline H. nana/Chilomastix mesnili/E. hartmanni & 1 & 1 & 0 & o & 1 \\
\hline Total & 80 & $39(0.8 \%)$ & $41(6.2 \%)$ & 32 (1.1\%) & $48(2.0 \%)$ \\
\hline $\mathrm{p}$ value & & & & & \\
\hline
\end{tabular}




\section{Discussion}

An estimated 3.5 billion people-roughly half of the world's population-have intestinal parasitoses, which cause almost 450 million deaths every year. The problem is particularly serious in endemic areas with poor sanitation, but parasitic infections are also becoming more common in non-endemic areas as a result of intensified immigration and travel [1].

Very little is known about the prevalence of intestinal protozoa and helminthes in Italy [9]. The present study shows that, over a 30 -month period, $8.8 \%$ of the patients referred to a large teaching hospital in Rome for ova and parasite analysis of stool samples harbour at least one species of pathogenic parasite.

The infection rate was lowest in children under five years of age and peaked in the 5-14 year-old group, declining progressively thereafter. The frequency of parasitic infections was found to be associated with patient, sex and nationality. The prevalence was substantially higher (almost 20\% (127/656)) among the non-Italian patients of our study, and even higher rates have been reported in the immigrant population living in southern Italy $(61.9 \%)$ [18]. On the whole, intestinal parasites were more common in males, although certain species, such as A. lumbricoides and Taenia spp., were detected more often in females.

Overall, Blastocystis hominis was the most common parasite encountered in this study. It was detected in $7.1 \%(378 / 5,351)$ of the patients we examined $(14.1 \%$ $(93 / 656)$ of the non-Italians and $7.5 \%(184 / 2,438)$ of the males). Blastocystis is an enteric protozoan that parasitises humans and many animals. It has a worldwide distribution and is often the most commonly isolated organism in parasitological surveys [8-19]. Accumulating evidence (epidemiological, in vivo, and in vitro) strongly suggests that Blastocystis is a pathogen [20]. Many genotypes exist in nature, and recent observations indicate numerous zoonotic genotypes also infect humans. Tan et al. have suggested that conflicting observations on the pathogenesis of Blastocystis stem from genetic diversity within the species, which includes both pathogenic and non-pathogenic genotypes [19]. The controversial pathogenicity of Blastocystis has been attributed to subtype variations in virulence, and while more recent studies seem to support this view, other factors also appear to contribute to the clinical outcome of the infection [19].

The second most common species in our study population was Giardia intestinalis. This common, ubiquitous flagellated protozoan has a significant impact on public health. Giardiasis is characterised by high prevalence, and it frequently causes major outbreaks and substantial effects on the growth and cognitive functions of infected children [21]. Giardia generally causes a self-limited illness characterised by diarrhoea, abdominal cramps, bloating, weight loss, and malabsorption. However, asymptomatic infections are frequent, especially in developing countries [22]. Infection rates are generally lower in industrialised countries, and figures ranging from $0.4 \%$ to $6.2 \%$ have been reported in Italy [23]. The overall prevalence observed in the present study was $1.3 \%$ (69/5351), but the rate in children less than 15 years of age was three times higher (4.8\% (38/797)). Rates were also higher in the non-Italian subgroup $(5 \%(33 / 656)$ vs $0.8 \%$ $(36 / 4,695)$ in Italians), and $78.6 \%(22 / 28)$ of infected patients aged less than 15 years were non-Italians. High infection rates have been reported for certain relatively poor regions in developed countries, and Giangaspero et al. reported a rate of $42.9 \%$ in a small, socially deprived Roma community in Italy [24]. A lower prevalence ( $4.5 \%)$ was found, however, in immigrants living in southern Italy [18].

The third most common species, although only detected in 11 patients, was Entamoeba histolytica. Entamoeba spp. can cause harmless colonisation of the intestine or severe infections characterised by invasion of the colon wall and damage to other host tissues, such as the liver, lung, and brain (amoebiasis). In most cases, a clinical diagnosis of amoebiasis can be confirmed microbiologically, generally by light microscopic visualisation of parasites in a wet smear or stained specimens. This procedure is simple and inexpensive, but it has several limitations. The most important is that it cannot distinguish between the cysts and trophozoites of $E$. histolytica (the disease-causing species), E. dispar (which is non-pathogenic), and E. moshkovskii, the amphizoic amoeba that occasionally infects humans. In addition, multiple samples often have to be examined, and the diagnosis can be even more difficult when there are cysts of different species of Entamoeba, Iodamoeba, or Endolimax [25]. Differentiating between these three species has become increasingly important (for diagnosis and for epidemiological studies) since sporadic cases of human infection with E. moshkovskii were reported [26]. Recent findings indicate that this species is highly prevalent in young children in Bangladesh, where it is often associated with $E$. histolytica and E. dispar [27]. In our study, E. histolytica and/ or $E$. dispar were detected by microscopy in 33 patients. However, when these cases were analysed with molecular tools, the presence of $E$. histolytica was confirmed in only 11 patients (10 of whom were Italians): the other 22 (18 Italians) were infected with E. dispar, Isospora belli, E. intestinalis, and Cryptosporidium parvum were detected only in immunocompromised patients, all but one of who were HIV-infected. Helminthes were found in only $0.5 \%(27 / 5,351)$ of our patients.

Our findings confirm that certain intestinal parasites, such as E. histolytica, C. cayetanensis, S. stercoralis, and $H$. nana, are not restricted to endemic areas in the tropics. However, our study has certain limitations that must be acknowledged. Our analysis was retrospective, and it was performed at a single hospital, so the results are not necessarily applicable to other settings. However, this shortcoming is to some extent 
outweighed by the large size of the sample population and the fairly large variety of the parasites identified. In addition, the relationship between parasitic infection rates and nationality has been consistently demonstrated in other studies [18-24].

In conclusion, knowledge of the organisms responsible for intestinal parasite infections in non-endemic areas is an essential step toward effective patient care and the implementation of appropriate control measures. Our findings demonstrate that intestinal parasitoses must be considered in the differential diagnosis of gastrointestinal diseases even in industrialised areas. Examination of multiple stool specimens per patient is still the recommended approach for excluding parasitic infection [28]. We agree that multiple stool analyses for ova and parasites can be clinically useful in populations with increased risk of infection, but it also is important to identify populations at low risk for infection, such as that in our study. Stool examinations are costly and labour-intensive, and routine requests should be avoided unless they are supported by epidemiological (e.g. international travel, unsafe drinking water) and clinical features (e.g. diarrhoea for more than seven days, especially if the patient is immunocompromised). In this context, close collaboration between physicians and clinical microbiologists should produce significant positive effects.

\section{Acknowledgments}

We thank Marian Kent for editorial assistance.

\section{References}

1. World Health Organization (WHO). The world health report 2004: changing history: Geneva: WHO, 2004.

2. Ortega CD, Ogawa NY, Rocha MS, Blasbalg R, Caiado AH, Warmbrand G, et al. Helminthic diseases in the abdomen: an epidemiologic and radiologic overview. Radiographics. 2010;30(1):253-67.

3. Guerrant RL, Oria R, Bushen OY, Patrick PD, Houpt E, Lima AA. Global impact of diarrheal diseases that are sampled by travelers: the rest of the hippopotamus. Clin Infect Dis. 2005;41 Suppl 8:S524-30.

4. Orlandi PA, Chu DMT, Bier JW, Jackson GJ. Parasites in the food supply. Food Technol. 2002; 56(4): 72-81.

5. Stark D, Fotedar R, van Hal S, Beebe N, Marriott D, Ellis JT, et al. Prevalence of enteric protozoa in human immunodeficiency virus (HIV)-positive and HIV-negative men who have sex with men from Sydney, Australia. Am J Trop Med Hyg. 2007;76(3):549-52.

6. Hennessy TW, Marcus R, Deneen V, Reddy S, Vugia D, Townes J, et al. Survey of physician diagnostic practices for patients with acute diarrhea: clinical and public health implications. Clin Infect Dis. 2004;38 Suppl 3:S203-11.

7. Kirkwood BR. Diarrhoea. In: Feachem RG, Jamison DT, editors. Disease and mortality in sub-Saharan Africa. New York: Oxford University Press; 1991:134-6.

8. Aguiar JI, Gonçalves AQ, Sodré FC, Pereira Sdos R, Bóia MN, de Lemos ER, et al. Intestinal protozoa and helminths among Terena Indians in the State of Mato Grosso do Sul: high prevalence of Blastocystis hominis. Rev Soc Bras Med Trop. 2007;40(6):631-4.

9. Peruzzi S, Gorrini C, Piccolo G, Calderaro A, Dettori G, Chezzi C. Prevalence of intestinal parasites in the area of Parma during the year 2005. Acta Biomed. 2006;77(3):147-51.

10. Gonin P, Trudel L. Detection and differentiation of Entamoeba histolytica and Entamoeba dispar isolates in clinical samples by PCR and enzyme-linked immunosorbent assay. J Clin Microbiol. 2003;41(1): 237-41.

11. Johnson DW, Pieniazek NJ, Griffin DW, Misener L, Ros JB. Development of a PCR protocol for sensitive detection of Cryptosporidium oocysts in water samples. Appl Environ Microbiol. 1995;61 (11):3849-55.

12. Visvesvara GS, da Silva AJ, Croppo GP, Pieniazek NJ, Leitch GJ, Ferguson D, et al. In vitro culture and serologic and molecular identification of Septata intestinalis isolated from urine of a patient with AIDS. J. Clin. Microbiol.1995;33(4):930-6.

13. del Aguila C, Lopez-Velez R, Fenoy S, Turrientes C, Cobo J, Navajas R, et al. Identification of Enterocytozoon bieneusi spores in respiratory samples from an AIDS patient with a 2-year history of intestinal microsporidiosis. J Clin Microbiol. 1997;35(7):1862-6.

14. Da Silva AJ, Slemenda SB, Visvesvara GS, Schwartz DA, Wilcox CM, Wallace S, et al. Detection of Septata intestinalis (microsporidia) cali et al. 1993 using polymerase chain reaction primers targeting the small subunit ribosomal RNA coding region. Mol Diagn. 1997;2(1):47-52.

15. Yoder KE, Sethabutr O, Relman DA. PCR-based detection of the intestinal pathogen Cyclospora.. In: Persing DH, editors. PCR protocols for emerging infectious diseases, a supplement to diagnostic molecular microbiology: principles and applications. Washington, DC: ASM Press; 1996: 169-76.

16. Visvesvara GS. In vitro cultivation of microsporidia of clinical importance. Clin Microbiol Rev. 2002;15(3):401-13.

17. Garcia LS. Diagnostic medical parasitology. 4th edition. Washington,DC: American Society for Microbiology; 2001.

18. Gualdieri L, Rinaldi L, Petrullo L, Morgoglione ME, Maurelli MP, Musella V, et al. Intestinal parasites in immigrants in the city of Naples (southern Italy). Acta Trop. 2011;117(3):196-201.

19. Tan KSW. New insights on classification, identification, and clinical relevance of Blastocystis spp. Clin Microbiol Rev. 2008;21 (4): 639-65.

20. Shlim DR, Hoge CW, Rajah R, Rabold JG, Echeverria P. Is Blastocystis hominis a cause of diarrhea in travelers? A prospective controlled study in Nepal. Clin Infect Dis; 1995; 21(1):97-101.

21. Feng Y, Xiao L. Zoonotic potential and molecular epidemiology of Giardia Species and giardiasis. Clin Microbiol Rev. 2011;24(1):110-40.

22. Thompson RC. Giardiasis as a re-emerging infectious disease and its zoonotic potential. Int J Parasitol. 2000;30:1259-67.

23. Crotti D, D’Annibale ML, Fonzo G, Lalle M, Caccio SM, Pozio E. Dientamoeba fragilis is more prevalent than Giardia duodenalis in children and adults attending a day care centre in Central Italy. Parasite. 2005;12(2):165-70.

24. Giangaspero A, Berrilli F, Brandonisio O. Giardia and Cryptosporidium and public health: the epidemiological scenario from the Italian perspective. Parasitol Res. 2007;101(5):1169-82.

25. González-Ruiz A, Haque R, Aguirre A, Castañón G, Hall A, Guhl $F$, et al. Value of microscopy in the diagnosis of dysentery associated with invasive Entamoeba histolytica. J Clin Pathol. 1994;47(3):236-9.

26. Clark CG, Diamond LS. The Laredo strain and other Entamoeba histolytica-like amoebae are Entamoeba moshkovskii. Mol Biochem Parasitol. 1991;46(1):11-8.

27. Ali IKM, Hossain MB, Roy S, Ayeh-Kumi PF, Petri WA Jr, Haque $\mathrm{R}$, Clark CG. Entamoeba moshkovskii infections in children, Bangladesh. Emerg. Infect Dis. 2003;9(5):580-4.

28. Branda JA, Lin TY, Rosenberg ES, Halpern EF, Ferraro MJ. A rational approach to the stool ova and parasite examination. Clin Infect Dis. 2006;42(7):972-8. 